\title{
Article
}

\section{Predicting the Criminal Records of Male- on-Female UK Homicide Offenders From Crime Scene Behaviors}

\author{
Almond, Louise, Martin, Elias and Mcmanus, Michelle Ann \\ Available at http://clok.uclan.ac.uk/31082/ \\ Almond, Louise, Martin, Elias and Mcmanus, Michelle Ann ORCID: 0000-0002- \\ 0095-1071 (2021) Predicting the Criminal Records of Male-on-Female UK \\ Homicide Offenders From Crime Scene Behaviors. Journal of Interpersonal \\ Violence, 36 (21-22). NP11852-NP11876. ISSN 0886-2605
}

It is advisable to refer to the publisher's version if you intend to cite from the work. http://dx.doi.org/10.1177/0886260519888522

For more information about UCLan's research in this area go to http://www.uclan.ac.uk/researchgroups/ and search for <name of research Group>.

For information about Research generally at UCLan please go to http://www.uclan.ac.uk/research/

All outputs in CLoK are protected by Intellectual Property Rights law, including Copyright law. Copyright, IPR and Moral Rights for the works on this site are retained by the individual authors and/or other copyright owners. Terms and conditions for use of this material are defined in the policies page.

\section{CLoK}

Central Lancashire online Knowledge www.clok.uclan.ac.uk

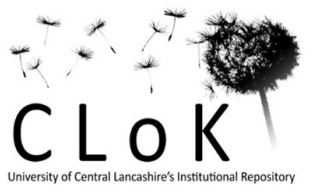




\title{
PREDICTING THE CRIMINAL RECORDS OF MALE-ON-FEMALE UK HOMICIDE OFFENDERS FROM CRIME SCENE BEHAVIORS
}

\author{
Dr Louise Almond ${ }^{1}$ \\ Elias Matin ${ }^{1}$ \\ Dr Michelle McManus ${ }^{2}$ \\ ${ }^{1}$ University of Liverpool \\ School of Psychology \\ Liverpool \\ UK \\ lalmond@liverpool.ac.uk \\ ${ }^{2}$ Public Health Wales \\ Wrexham \\ Wales \\ UK
}

Policy, Research \& International Development 


\section{Abstract}

Offender profiling follows the idea that if offenders' crime scene actions can be empirically linked to their background characteristics, it will be possible to predict one from the other (Canter, 2011). There is a lack of research exploring whether homicide offenders' crime scene actions are predictive of their criminal histories, despite the potential utility of such information (Almond, McManus, Bal, O'Brien, Rainbow, \& Webb, 2018). The current study addresses this gap in the literature.

A sample of 213 adult male-on-female homicides with sexual or unknown motive was drawn from a UK-wide database. Relationships between 13 preconviction variables and 29 crime scene behaviors were explored using a bivariate statistical approach. Subsequently, binary logistic regression models were used to predict the presence, or absence, of specific pre-convictions based on a combination of offence behaviors. Analyses highlighted 16 statistically significant associations between key offence behaviors and previous convictions, these associations were often "less likely" to result in previous conviction. The analysis failed to find any association for various other variables, most notably sexual pre-convictions. Results indicate offenders' criminal histories can be predicted from their offence behaviors, though not all pre-convictions may be similarly suited. Implications for practice are discussed. 


\section{Introduction}

The majority of homicides in the United Kingdom are solved relatively quickly after the offence occurred (Nicol, Innes, Gee, \& Feist, 2004). In about one quarter of homicide cases, however, investigators are confronted with complex scenarios, in which possible suspects and relationships between involved individuals cannot be identified quickly (Francis et al., 2004). Homicides involving stranger or child victims, sexual elements, an unknown motive, or serial offences are usually more difficult to detect and consume considerable amounts of police resources, attract increased media attention, and are often perceived as especially severe, baring the potential to negatively impact the public's general fear of crime and, thus, their perceptions of police efficiency (Cole \& Brown, 2014; Francis et al., 2004; Innes, 2003).

Within the UK, practitioners' experience in such difficult-to-solve cases is often complemented with empirically grounded investigative support provided by Behavioral Investigative Advisers (BIAs, Rainbow \& Gregory, 2009). One of the core competencies of BIAs is their ability to make logical, evidence-based inferences on likely offender characteristics based on the behavioral assessment of a crime scene. This form of investigative support, commonly referred to as offender profiling, can be a valuable instrument to assist police in prioritising potential nominals and efficiently directing scarce resources in demanding investigations (Cole \& Brown, 2014; Rainbow \& Gregory, 2009). Offender profiling generally rests on the assumption of homology, i.e. offenders who commit crimes in a similar manner will also share similar background characteristics (Alison, Bennell, Mokros, \& Ormerod, 2002; Mokros \& Alison, 2002). Based on this tenet, offender profiling seeks to establish so-called "A to $C$ equations", investigating if and how crime scene actions $(A)$ can be linked to offender background characteristics $(\mathrm{C})$, in order to allow for predictive 
inferences in unsolved criminal cases (Canter, 2011). With regard to practical utility, profiling inferences made by BIAs should ideally relate to offender background information that is overt, objective, and readily available to investigators, such as the offender's likely age, sex, or previous criminal convictions (Alison et al., 2005). In addition, investigative advice given by BIAs must be transparent as to how adequately and reliably it is backed by scientific research (Alison, Smith, Eastman, \& Rainbow, 2003; Almond, Alison, \& Porter, 2007). Taken together, this highlights the need for a broad and pragmatic research foundation on which to base profiling claims on.

A number of international studies have extended the available evidence base for offender profiling attempts in homicide cases over the last decades (e.g. Cole \& Brown, 2014; Francis et al., 2004; Fujita et al., 2016; Horning, Salfati, \& Crawford, 2010; Salfati \& Canter, 1999; Santtila, Häkkänen, Canter, \& Elfgren, 2003; Trojan \& Salfati, 2011). However, relatively few studies have examined specifically whether homicide offenders' criminal histories can be inferred from their crime scene actions. Criminal history profiling follows the idea that an offender's prior criminal experience, such as encounters with the criminal justice system or previously successful criminal strategies, will influence future behaviors this offender exhibits in the commission of a crime (Beauregard \& Bouchard, 2010; Beauregard \& Martineau, 2013; Davies et al., 1997). The current lack of studies exploring links between homicide offenders crimes scene actions and their pre-convictions is unfortunate given the potential usefulness of such information to investigations, as 1) most homicide offenders appear to have criminal antecedents of some kind (Broidy, Daday, Crandall, Sklar, \& Jost, 2006; Cole \& Brown, 2014; Greenall \& Richardson, 2015; Soothill, Francis, Ackerley, \& Fligelstone, 2002) and 2) information on previous criminal convictions is easily 
available to investigators through police databases as long as their offending has been in the UK (Alison et al., 2005).

Furthermore, the few existing studies so far are divided by a fundamental dispute in the general offender profiling literature, concerning which statistical approach should be preferred for linking crime scene actions to offender characteristics (Alison, Goodwill, Almond, Heuvel, \& Winter, 2010). Some authors have favoured direct bivariate associations to explore the relationship between single offence behaviors and prior offences (e.g. Almond et al., 2018; Cole \& Brown, 2014; Davies et al., 1997; Lea, Hunt, \& Shaw, 2011; Scott, Lambie, Henwood, \& Lamb, 2006; ter Beek, van den Eshof, \& Mali, 2010). In the context of stranger rape, for example, Almond et al. (2018) found in their replication of the classic Davies et al. (1997) study that stranger rapists who forced their entry were 2.5 times more likely to have a previous conviction for burglary, whereas offenders who disabled their victim's phone were nearly 5 times more likely to have previously been convicted for a violent crime. Contrarily, other authors have employed a thematic approach, which investigates how themes or typologies of crime scene actions relate to clusters of offender characteristics (e.g. Horning et al., 2010; Salfati, 2000; Salfati \& Canter, 1999; Santtila et al., 2003; Trojan \& Salfati, 2011). While the dispute over the most appropriate statistical approach for offender profiling might not yet be ultimately resolved, there is some evidence that direct bivariate associations outperform thematic approaches in their predictive power (Goodwill, Alison, \& Beech, 2009).

Despite the general dearth of research and the ongoing methodological dispute, some studies have shed light on possible relationships between offence behaviors and previous convictions in the context of homicide (e.g. Cole \& Brown, 2014; Horning et al., 2010; Salfati \& Canter, 1999; Trojan \& Salfati, 2011). Employing 
a direct, bivariate statistical approach on a sample of difficult-to-detect homicide cases, Cole and Brown (2014) found, for example, that killers who were under the influence of alcohol or drugs during the offence, were more than twice as likely to have a previous conviction for violent offences, whereas murderers who took pieces of their victim's clothing with them were nearly 2.5 times more likely to have been previously arrested for a sexual offence. Using a more thematic approach, Horning et al. (2010) demonstrated that homicide offenders, who showed some degree of specialisation towards violent, sexual, or acquisitive crimes in their criminal histories, were more likely to engage in goal directed behaviors at the crime scene, such as controlling the victim or sexually and materially exploitative behaviors, when compared to non-specialist offenders.

However, the majority of the existing studies thus far are arguably based on non-contemporary samples and have either contained a limited number of previous conviction categories (Cole \& Brown, 2014) or have grouped multiple previous convictions into broader clusters or typologies (Horning et al., 2010; Salfati \& Canter, 1999; Trojan \& Salfati, 2011). Thus, exploring a larger and more specific set of previous conviction variables may help to not only answer whether offenders' criminal histories can be reliably predicted from their crime scene actions, but also whether certain pre-convictions may be better suited for prediction than others. In addition, previous studies have mostly analysed samples including both male and female killers, even though research has repeatedly highlighted differences in crime scene behaviors, criminal histories, and general psychological functioning between the two groups (Jurik \& Winn, 1990; Putkonen, Weizmann-Henelius, Lindberg, Rovamo, \& Häkkänen-nyholm, 2011; Trägårdh, Nilsson, Granath, \& Sturup, 2016), Similarly, prior studies indicate that offenders with female victims may differ from killers that 
target male victims (Muftić \& Baumann, 2012), indicating more extensive arrest records and differences in weapon involvement and methods of killing in femicide offenders (Goetting, 1991). There may, therefore, be a need to specialise predictive profiling efforts towards what appear to be distinct homicidal offender subpopulations.

In conclusion of the theoretical, practical, and methodological considerations outlined above, the study proposed here aimed to explore the relationships between a large set of homicide offender pre-convictions and specific crime scene behaviors using a bivariate statistical approach. The sample utilised was focussed on a large, yet specific homicide offender sub-group, i.e. adult male-on-female offenders with adult victims. To increase the practical applicability of any findings, this study used a contemporary sample of investigative policing data drawn from a database of hard-to-solve homicide cases with sexual or unknown motive. In doing so, this study addresses the need for a separate, offence-specific, up-to-date empirical basis BIAs can refer to when aiming at predicting an unknown offender's likely criminal history in cases of unsolved homicide.

\section{Method}

\section{Database}

The present study is based on secondary case data provided by the National Crime Agency's (NCA) Serious Crime Analysis Section (SCAS). SCAS operates a unique, UK-wide database holding details of rape, homicide, and abduction cases that meet specific criteria. For homicide, these criteria include cases where BIA support may typically be requested, i.e. homicides with a known sexual motive as well as homicides with unknown motive, in which the offender-victim relationship is 
unknown or stranger (Rainbow \& Gregory, 2009). SCAS receive case files from all UK police forces, which are then coded and entered into a Violent Crime Linkage Analysis System (ViCLAS) database involving a rigorous quality control process and highly trained staff to ensure input accuracy and interrater reliability (Almond et al., 2018). The dataset utilised herein was provided to the author in a clean, pre-coded, and anonymised form.

\section{Sample}

For this study, a sample of solved homicide cases involving a single female victim and a single male offender was drawn from ViCLAS by SCAS based on the following criteria: First, offences must have occurred between 1985 and 2017. Second, both victim and offender must have been adults (above the age of 16) at the time of the offence. Third, data must be taken from cases involving single offenders and single victims only. And finally, for serial homicides, only the first victim must be included in the dataset to avoid any biases resulting from an overrepresentation of certain serial offenders. After eliminating four cases in which no pre-conviction information was available, a final sample of 213 cases was obtained.

Sample demographics show that on average, offenders $(M=31.38, S D=9.42)$ were younger than victims $(M=37.83, S D=19.95)$ with most offenders being of European descent (89.2\%), in relation to offenders of African Caribbean (6.1\%), Asian (2.8\%), and Oriental or Arabic (1.4\%) descent. One offender was classified as of unknown descent (0.5\%). Table 1 displays the frequencies of relationships between offenders and their victims in this sample. 


\section{Procedure}

Variables extracted from ViCLAS related to either previous convictions of the offender at the time of the index offence or specific behavioral offence characteristics that were observed at the crime scene. Offence behavior variables were pre-coded by SCAS in a dichotomous format with 1 indicating presence and 0 indicating absence (or unknown status) of specific behaviors and crime scene characteristics. A total of 29 offence behavior variables (see Table 2) broadly falling into the categories of sexual behaviors, weapon involvement, method of killing, body disposal, theft, precautions, and other behaviors, were selected for the analysis based on a number of previous studies on homicide (Cole \& Brown, 2014; Greenall \& Richardson, 2015; Pell, 2017; Wright, 2017).

Some low frequency variables (e.g. different recorded types of vaginal penetration) were combined into broader, superordinate categories (e.g. general vaginal penetration). Notably, variables relating to precautions taken were grouped to reflect whether offenders manipulated the crime scene (e.g. destroyed forensics), the victim (e.g. blindfolding, gagging), or themselves (e.g. wearing gloves, condoms) to avoid detection or facilitate the offence. Variables relating to the method of killing (blunt force, sharp force, asphyxia/strangulation) and variables concerning theft from the crime scene (personal items, valuables, clothing stolen) were coded from free text boxes by the author. It should be noted that in cases of homicide, it is generally unlikely to obtain a complete and exhaustive picture of a killer's offence behaviors solely through observing the crime scene. This implicates that 1) the absence of a recorded variable does not necessarily equal the absence of the respective behavior, and 2) the presence of a recorded variable cannot guarantee that the offender carried out that behavior 
In addition to these offence behavior variables, a total of 13 pre-convictions (see Table 3) were selected, based on variables used in previous studies on sexual homicide (Greenall \& Richardson, 2015) and rape (Almond et al., 2018).

\section{Statistical Analysis}

This study aimed to replicate the methodology originally introduced by Davies et al. (1997) for their investigation of stranger rapists' pre-convictions in a new context - that of male-on-female homicide offenders. Specifically, this study adopted the statistically more sophisticated approach recently employed by Almond, et al. (2018) in their contemporary replication of the Davies et al. (1997) study.

Data was analysed in two stages. In stage one, separate chi-square tests were employed to investigate whether any direct associations between offence behavior variables and conviction variables could be identified. Where test assumptions were violated (expected frequencies must be $>5$ in each cell), Fisher's exact tests were used (Field, 2013). In order to account for multiple testing on the same sample, Bonferroni-Holm corrections were applied to adjust p-values. To further qualify any significant associations, Odds Ratios (OR) were calculated to assess the likelihood of an offender having a specific pre-conviction based on the presence or absence of single behaviors during the offence. An $O R>1$ indicates that the probability of a pre-conviction $A$ is increased if an offence behavior $B$ was observed, whereas the probability of $A$ is decreased if $B$ was not observed (and vice versa for ORs < 1) (Liberman, 2005). According to Chen, Cohen, and Chen (2010), the strength of the identified associations can be considered low $(\mathrm{OR}<1.5)$, medium (OR 1.5 - 5), or high $(\mathrm{OR}>5)$. 
In stage two, logistic regression models were used to predict an offender's previous convictions based on a combination of significant offence behavior variables identified in stage one. A separate forced-entry logistic regression was performed for each pre-conviction type. In addition, it was assessed how much each predictor variable contributed to the predictive accuracy of the model and if these contributions were statistically significant. To evaluate their usefulness to practitioners, each of the models' ability to predict a certain pre-conviction was compared with the "best guess" investigators would face without knowledge of any offence behavior (i.e. a guess based only on the base rate of a particular pre-conviction in this sample). As an additional measure of model performance, Receiver Operating Characteristics (ROC) Area Under the Curve (AUC) values were calculated.

\section{Results}

\section{Descriptive Statistics}

Table 2 displays the frequency of offence behavior variables in this sample. While only a minority of offenders had previous convictions for sexual crimes $(14.6 \%)$, the majority of cases in this dataset $(73.2 \%)$ can be classified as sexual homicides based on behaviors observed from the crime scene, according to the criteria proposed by Ressler et al. (1988). More specifically, most of the cases involved some degree of disrobement of the victim (66.2\%), whereas overt sexual behaviors $(41.8 \%)$ and injuries to victims' sexual areas (16.4\%) were less commonly observed. A relatively large group of offenders in this sample engaged in some form of theft from the victim (44.1\%). Similarly, a sizeable minority took precautions in relation to the homicide crime $(40.8 \%)$.

Frequencies of offenders' previous convictions are displayed in Table 3. Most offenders (73.7\%) had been convicted at least once prior to the index homicide, with 
theft $(45.1 \%)$, violence $(39.0 \%)$, burglary $(35.2 \%)$, and criminal damage $(33.3 \%)$ being the most frequent conviction categories. However, there is also a sizeable minority of offenders (26.3\%) without any previous criminal history.

\section{Exploring Male-on-Female Homicide Offenders' Behaviors and Conviction} Histories

To explore whether any bivariate associations between single crime scene behaviors and specific pre-convictions could be found, chi-square analyses were conducted. No significant associations were found for several crime scene behavior variables as well as the pre-conviction variables criminal record, drugs, public order, robbery and sexual crimes, whereas arson and homicide were excluded from the analysis due to their extremely low frequency within this sample. A total of 16 statistically significant relationships $(p<.05)$ were obtained, for which Table 4 shows Odds Ratios as a measure of effect size and direction.

\section{Precautionary behaviors.}

If an offender took precautions relating to the crime scene, he was nearly 3 times less likely $(\mathrm{OR}<1$, therefore $1 / 0.36=2.78)$ to have a previous conviction for weapon-related crimes, $\chi^{2}(1)=4.213, p=.040$.

\section{Sexual behaviors.}

If vaginal penetration did occur during the homicide, the likelihoods of several pre-convictions were reduced significantly, with theft, $\chi^{2}(1)=5.910, p=.015$, and violence, $\chi^{2}(1)=4.626, p=.031$, being 2 times and weapon-related crimes nearly 2.5 times less likely, $\chi^{2}(1)=4.039, p=.044$. Similarly, pre-convictions for violent crimes were 2.5 times less likely if the offender moved the victim's clothing to expose her, 
$\chi^{2}(1)=4.054, p=.044$. Contrarily, a previous conviction for fraud was 2 times more likely if the victim was found naked, $\chi^{2}(1)=3.885, p=.049$.

\section{Weapon involvement.}

If there was evidence that an offender brought a weapon to the crime scene, pre-convictions for criminal damage, $\chi^{2}(1)=4.034, p=.045$, and theft, $\chi^{2}(1)=4.996$, $p=.025$, were about 2.5 times less likely, whereas prior violence-related convictions were nearly 3.5 times less likely, $\chi^{2}(1)=7.094, p=.008$. However, the use of a bludgeoning weapon increased offenders' likelihood of having a previous conviction for fraud, $\chi^{2}(1)=5.102, p=.024$, making it more than 2 times as likely.

\section{Method of killing.}

Killing the victim through blunt force increased an offender's likelihood of having a previous criminal damage conviction, $\chi^{2}(1)=4.393, p=.036$, making it nearly twice as likely. Associated in the opposite direction, weapon-related pre-convictions were almost 3.5 times less likely, $\chi^{2}(1)=7.561, p=.006$, if death was caused through asphyxia/strangulation.

\section{Other behaviors.}

The use of a vehicle in association with the index homicide made a pre-conviction for criminal damage nearly 2.5 times less likely $\chi^{2}(1)=5.932, p=.015$. If the offence comprised an element of arson, the likelihood of prior convictions for violent crimes $(p=.030)$, and burglary $(p=.010)$, were increased (due to the low frequency of arson as an offence element, Fisher's exact tests are reported). Similarly, a burglary pre-conviction was more than 2.5 times more likely if a burglary element was present in the index homicide, $\chi^{2}(1)=8.213, p=.004$. 
After applying Bonferroni-Holm corrections (dividing the uncorrected $\alpha=.05$ by the number dependent variables $\mathrm{k}=11, \alpha_{c o r r}=.0045$ ), only the association of burglary element with burglary pre-conviction reached statistical significance. Therefore, results obtained so far should be interpreted with caution.

\section{Logistic Regression Models}

The significant bivariate associations identified in the first step of the analysis were then entered into binary logistic regression models to predict the presence or absence of a specific pre-conviction based on a combination of offence behaviors.

\section{Burglary.}

Using a logistic regression model, it was attempted to predict whether offenders did or did not have a previous conviction for burglary based on the presence or absence of a burglary element in the index homicide offence (see Table 5). While the variable arson element was also found to be associated with burglary pre-convictions in the previous step, it had to be excluded from the logistic regression analysis as it violated basic assumptions of the model (expected cell frequencies were less than 5 in more than $20 \%$ of cells if arson element was included). The remaining one-factorial model reached statistical significance, $\chi^{2}(1)=7.925, p=.005$, with burglary element contributing significantly to the model $(p=.005)$, as indicated by the Wald criterion. The whole model explained between 3.7\% (Cox and Snell $R^{2}$ ) and $5.0 \%$ (Nagelkerke $R^{2}$ ) of the variance in the dependent variable burglary preconviction, correctly classifying $66.2 \%$ of all cases. 


\section{Criminal Damage.}

Two of the three previously identified crime scene behaviors, namely vehicle used and death blunt force, were entered into a logistic regression (see Table 5) to predict the presence or absence of a criminal damage pre-conviction (weapon brought by offender was excluded due to violations of model assumptions). The resulting model reached statistical significance, $\chi^{2}(2)=10.801, p=.005$, with both vehicle used $(p=.016)$ and death blunt force $(p=.034)$ contributing significantly to the model. Overall, the model correctly classified $66.7 \%$ of all cases, explaining between $4.9 \%$ (Cox and Snell $R^{2}$ ) and 6.9\% (Nagelkerke $R^{2}$ ) of the variance in the pre-conviction variable criminal damage.

\section{Fraud.}

The two significant crime scene behaviors of victim naked and bludgeoning weapon were entered into a logistic regression model (see Table 5) to predict whether offenders did or did not have a previous fraud conviction, with the resulting model being statistically significant, $\chi^{2}(2)=8.450, p=.015$, and both victim naked $(p=.050)$ and bludgeoning weapon $(p=.026)$ contributing significantly to the model. The full model accounted for between 3.9\% (Cox and Snell $R^{2}$ ) and 6.0\% (Nagelkerke $R^{2}$ ) of the variance in fraud pre-conviction status, correctly classifying $78.9 \%$ of all cases.

Theft.

Chi-square analyses previously identified two crime scene behaviors to be significantly associated with theft pre-conviction status. A logistic regression model (see Table 5) including both variables (vaginal penetration and weapon brought by offender) reached statistical significance, $\chi^{2}(2)=11.474, p=.003$, and both vaginal 
penetration $(p=.014)$ and weapon brought by offender $(p=.025)$ made significant contributions to the prediction. This model correctly classified $61.0 \%$ of the cases and explained between 5.2\% (Cox and Snell $R^{2}$ ) and 7.0\% (Nagelkerke $R^{2}$ ) of the variance in theft pre-conviction status.

\section{Weapons.}

The crime scene behaviors precautions scene, vaginal penetration, and death asphyxia/strangulation were identified as significantly related with weapon-related pre-convictions. Except for vaginal penetration (excluded due to violation of assumptions), all of these variables were entered into a logistic regression model (see Table 5) that reached statistical significance, $\chi^{2}(2)=13.533, p=.001$, with both precautions scene $(p=.039)$ and death asphyxia/strangulation $(p=.007)$ contributing significantly to the model. In total, the model classified $81.7 \%$ of the cases correctly and accounted for between 6.2\% (Cox and Snell $R^{2}$ ) and 10.0\% (Nagelkerke $R^{2}$ ) of the variance in weapons pre-conviction status.

\section{Violence.}

Of the four crime scene behaviors previously identified to be associated with violence-related pre-convictions, only vaginal penetration and weapon brought by offender were included in a logistic regression model as depicted in Table 5 (arson element and clothing moved to expose were excluded due to violations of model assumptions). This model successfully predicted the pre-conviction variable violence, $\chi^{2}(2)=12.795, p=.002$, and both vaginal penetration $(p=.028)$ and weapon brought by offender $(p=.009)$ contributed significantly to the model. Correctly classifying $61.0 \%$ of all cases, the model accounted for between $5.8 \%$ (Cox and Snell $R^{2}$ ) and $7.9 \%$ (Nagelkerke $R^{2}$ ) of the variance in violence pre-conviction status. 


\section{Prediction and performance of logistic regression models}

Mirroring the original Davies et al. (1997) paper, Table 11 shows the logit values of all logistic regression models produced in the current study. These models predict the probability of whether an offender does or does not have a specific pre-conviction based on the presence or absence of a combination of crime scene behavior for each case in the sample using a model equation. To predict the probability of a theft pre-conviction in a case in which, for example, the offender engaged in vaginal penetration, but did not bring a weapon to the crime scene, the log-odds would equal:

$.171($ constant $)-.768 * 1($ vaginal penetration $)-.949 * 0($ weapon $)=-.597$.

The probability of a theft pre-conviction would then be:

$$
\frac{e^{-.597}}{1+e^{-.597}} \text { or } \quad 35.5 \% \text {. }
$$

In terms of model performance, the percentage of cases correctly classified by the logistic regression models based on their probability estimations using crime scene information (criterion: $>50 \%$ vs. $<50 \%$ ) is only slightly higher (burglary, theft) or equal (criminal damage, fraud, weapons, violence) to the performance of a simple "best guess" approach that uses only base-rate pre-conviction information of this sample (e.g. probability of an offender having a fraud pre-conviction irrespective of his crime scene behavior is $21.1 \%)$. As an additional measure of the models' discriminant performances, ROC AUC analyses were conducted. AUC values displayed in Table 6 are equivalent to the probability with which proposed logistic regression models will assign a randomly chosen case, in which the offender did have a certain pre-conviction, with a higher probability estimation than a randomly chosen case, in which the offender did not have this pre-conviction (Fawcett, 2006). 
AUC probabilities range from $58,4 \%$ (burglary) to $66.2 \%$ (weapons), suggesting overall poor to medium model performances (Rice \& Harris, 2005)

\section{Discussion}

The purpose of this study was to explore whether male-on-female homicide offenders' criminal histories could be predicted from their crime scene actions. By using a contemporary set of investigative policing data and a large number of previous conviction variables, this study aimed at extending the available evidencebase for criminal history profiling in cases of hard-to-solve homicide. The present research successfully demonstrated that 1 ) single crime scene actions could be empirically linked to single previous conviction variables using a bivariate statistical approach and that 2) multivariate statistical models were able to predict the probability of a specific pre-conviction based on a combination of offence behaviors observed from the crime scene. This study, therefore, successfully replicated the methodological approach proposed by Davies et al. (1997) and later Almond et al. (2018) in a new criminal context, i.e. hard-to-solve male-on-female homicide cases. Theoretical and practical implications of the obtained results are proposed and discussed with regard to a number of methodological limitations.

First, results suggest that not all prior convictions may be similarly suited for prediction based on behavioral characteristics of a crime scene. While this study was successful in linking some pre-conviction variables to certain offence behaviors, it failed to find any empirical association for several other pre-convictions, namely criminal record, drugs, public order, robbery, and sexual crimes. The general finding that only some pre-convictions seem to be related to offence behaviors is mirrored in previous studies that have used a similar bivariate linking approach (e.g. Almond et 
al., 2018; Cole \& Brown, 2014), which lends some support to the assumption that the link between offender characteristics and crime scene behaviors in general may be highly idiosyncratic. Accordingly, it has been argued that homology as the core tenet of offender profiling (i.e. two offenders who commit a certain type of crime in a similar way will show similar characteristics) may only be valid for specific offence behaviors and single offender characteristics (e.g. Taylor, Snook, Bennell, \& Porter, 2015; ter Beek et al., 2010). This opposes the idea that broader offence behavior clusters (e.g. themes) could be empirically associated with a standard set of background characteristics (e.g. offender types), which indeed has proven difficult in prior research (Mokros \& Alison, 2002; Trojan \& Salfati, 2011). Therefore, it is argued here that further efforts are needed to isolate and understand direct links between key offence behaviors and individual background characteristics.

In the context of criminal history profiling, the few existing studies exploring these direct, bivariate relationships, however, differ in their findings on which preconvictions exactly could and could not be linked to crime scene behaviors. While both this study and Almond et al. (2018), for example, did not find any association between offence variables and a history of sexual crime, Cole and Brown (2014) found prior sexual offences to be positively associated with the lack of precautionary behaviors at the scene and theft of clothing from the victim. More studies will be needed to establish, whether some (and if so, which) pre-convictions may generally be better suited for prediction from crime scene behaviors than others, and whether differences exist with regard to the type of crime (e.g. rape vs. homicide), or subsamples of offenders (e.g. male vs. female offenders, targeting female vs. male victims). 
Among the key findings in the current study is the association of crimes containing a burglary element with a prior conviction for burglary (more than 2.5 times more likely). This finding is consistent with evidence for criminal specialisations among homicide offenders, which highlights a large sub-group displaying histories of predominantly instrumental crimes, such as theft, burglary, or robbery (Trojan \& Salfati, 2016). As most homicides in the current study contained overt, or covert sexual behaviors $(73.2 \%)$, it is interesting to note that for cases of stranger rape, the crime scene behavior forced entry has been identified as a significant predictor of prior convictions for acquisitive crime types (i.e. burglary, theft, robbery) in multiple studies (Almond et al., 2018; Davies et al., 1997; Scott et al., 2006). Previous research has further highlighted a link between sexual homicide and a history of burglary (e.g. Schlesinger \& Revitch, 1999), with some authors suggesting that repeat burglary offenders may escalate from non-contact burglaries towards burglaries featuring more serious, interpersonal offence elements depending on a number of circumstantial factors (Pedneault, Harris, \& Knight, 2015). Taken together, burglary elements within homicides and serious sexual crimes appear as key indicators of previous burglary crimes in the literature, even though a generalisation of this finding towards other types of acquisitive crimes (e.g. theft, robbery) could not be supported in the current study.

Interestingly, sexual behaviors were predominantly negatively associated with prior conviction variables in this sample. If vaginal penetration was observed, the likelihoods of prior theft, weapons, and violence pre-convictions were reduced, whereas clothing moved further decreased the likelihood of prior violence convictions. An exemption was found in prior fraud convictions being two times more likely if the victim was found naked. These findings have not yet been recorded, 
given that prior bivariate criminal history profiling studies either did not examine specific sexual behaviors (Almond et al., 2018), or did not find any relationships between sexual behaviors and prior convictions (Cole \& Brown, 2014). Similarly, behaviors indicating some degree of premeditation were also negatively associated with pre-conviction variables in the current sample, with weapon brought decreasing the likelihood of prior theft, violence, and criminal damage convictions and weapon-related pre-convictions being less likely if precautions concerning the crime scene were observed. While it may be tempting to derive theoretical implications from the present findings, it should be borne in mind that this study was very much exploratory and was neither conceptualised to explicitly test nor retrospectively allow for inferences on underlying psychological constructs that may explain the cause for the identified associations. This is generally the case in studies employing a direct, bivariate profiling approach (Crabbé et al., 2008). However, the present study's success in finding some offence behaviors predictive of homicide offenders' preconvictions has important practical implications.

In unsolved cases of homicide, the availability of an empirical basis that allows to estimate the probability of an offender having a certain pre-conviction based on his behaviors at the crime scene would undoubtedly be beneficial to the investigation. Using the predictive models identified in this study, such probabilities could be calculated at the beginning of an investigation. Outcomes may assist in prioritising potential nominals according to the degree of similarity between theirs and the most likely criminal history of the offender, as predicted by the models. Similarly, the statistical models proposed here may suggest new lines of enquiry if, for example, not all predictive behaviors included in the models have yet been confirmed as present or absent in a given investigation. Overall, this study may not only contribute 
to improving detection rates of homicide offences, it may also increase the efficiency with which police resources are allocated in homicide investigations, thereby reducing the time and financial efforts associated with apprehending offenders (Alison et al., 2010; Rainbow \& Gregory, 2009). Most importantly, the present findings are therefore directly relevant to the work of BIAs by providing an evidence base on which they are required to base their investigative claims and inferences on (Alison et al., 2003; Almond et al., 2007). The practical utility of the results obtained herein is, however, qualified by a variety of limitations.

\section{Limitations}

First, some statistical issues should be noted regarding the results in this study. To identify, which crime scene behaviors were significantly related to which offender pre-convictions, this study utilised multiple chi-squared tests, but only one of the identified relationships (burglary element with prior burglary conviction) remained significant after applying Bonferroni-Holm corrections. As the probability of obtaining false positive results is inflated when large numbers of tests are performed on the same sample (Asendorpf et al., 2013), it may, therefore, be that this study has identified some variables as linked, when in fact, they are not. Furthermore, while the sample in this study can be considered large $(N=213)$ regarding the context of hard-to-solve homicide, the sample size was relatively small in comparison to other studies that rely on logistic regression models (Cramer, 1999), resulting in the parameter estimations of the present models being less stable and potentially susceptible to biases (Field, 2013; Nemes, Jonasson, Genell, \& Steineck, 2009).

Second, measures of predictive accuracy indicated that the complex logistic regression models utilised in this study had an overall poor to medium performance, making them only slightly better than a guess based solely on pre-conviction 
frequencies in this sample. While this highlights the value of simple base rate information for offender profiling efforts, the models provided herein may still be useful in rare cases, in which crime scene behaviors indicate a divergence from the base rate norm (e.g. probability of theft pre-conviction $>50 \%$ if no vaginal penetration and no weapon brought vs. $45 \%$ base rate).

On a more conceptual level, this study was based on solved homicide cases only, therefore, excluding those offenders who may be most proficient in avoiding detection. It has been argued that measures other than prior convictions, such as previous charges or arrests, may be more indicative of an offender's criminal history (Almond et al., 2018). Therefore, generalisations from the current findings should be treated with some degree of caution. Caution is further advisable, as the data used herein was not explicitly collected for research purposes, but ultimately stemmed from police records. Although the data is subject to a rigorous quality control progress before being entered into the SCAS database, the completeness of the data cannot be guaranteed, especially regarding the level of detail requested for some of the offence behavior variables. Although all behaviors that were evident would have been coded, due to the fact that the victim is not able to report on the offender's behavior in a homicide, there is the potential that not all behaviors that occurred in the offence were coded. As this piece of applied research was conceptualised as a practical instrument for police investigations, reliance on policing data may arguably increase the ecological validity of this study (Mokros \& Alison, 2002).

There is also a potential bias in the results towards those who do not have a substantial previous criminal history. As behaviors such as sexual behaviors and weapon brought to the scene are more likely to be recorded due to forensic evidence i.e. semen or weapon left at the scence may be biased towards those that are less 
criminally competent which may then be reflected in their criminal history. There may be plenty of other cases with similar behaviors that occurred in the offence but are not evident - and this may be a reflection of the perpetrator's criminal competence/sophistication/history.

Finally, the proposed statistical models were constructed to optimise their predictive accuracy in the current sample, which may contain random errors and other idiosyncrasies, especially with regard to the small sample size (Levine, Blair, \& Carpenter, 2017). It is therefore important to validate the findings on a separate sample, in order to determine accuracy shrinkage and predictive performance for new cases, that were not used to construct the models (Cole \& Brown, 2014; ter Beek et al., 2010). As the present sample is exhaustive and contains all homicide cases that matched the inclusion criteria in the UK, further research would have to either rely on data from other countries or future cases from within the UK, raising questions of regional or temporal comparability between the samples.

\section{Conclusion}

In conclusion, this study has provided a broad empirical overview on links between a large set of offender criminal history variables and crime scene behaviors in cases of homicide. By proposing statistical models that allow for predictions of the most likely criminal history of an offender as indicated by his specific offence behaviors, the current results may be of practical utility to homicide investigations. However, as several statistical and conceptual limitations of this study must be considered, it is argued here that the current results should only be used for practical applications with appropriate caution and transparency towards the study's shortcomings. In the UK, this transparency is ensured by experienced BIAs through providing observational grounds, warrants, research backing, rebuttal(s), and an 
indication of strength for each advisory investigative claim made, following the principles of Toulmin's philosophy of argument (Alison et al., 2003; Rainbow, 2008). In this way, BIA advice can be useful to inform and justify subsequent decisions made by investigators. This approach enables a synergy of evidence-based research, such as the present one, and investigators' practical experience, which is ultimately directed at maximising efficiency and success in criminal investigations. 


\section{References}

Alison, L. J., Bennell, C., Mokros, A., \& Ormerod, D. (2002). The personality paradox in offender profiling: A theoretical review of the processes involved in deriving background characteristics from crime scene actions. Psychology, Public Policy, and Law, 8(1), 115-135. http://doi.org/10.1037/1076-8971.8.1.115

Alison, L. J., Goodwill, A., Almond, L., Heuvel, C., \& Winter, J. (2010). Pragmatic solutions to offender profiling and behavioral investigative advice. Legal and Criminological Psychology, 15(1), 115-132. http://doi.org/10.1348/135532509X463347

Alison, L. J., Goodwill, A. M., \& Alison, E. (2005). Guidelines for profilers. In L. J. Alison (Ed.), The forensic psychologist's casebook (pp. 235-248). Devon: Willan Publishing.

Alison, L. J., Smith, M. D., Eastman, O., \& Rainbow, L. (2003). Toulmin's philosophy of argument and its relevance to offender profiling. Psychology, Crime and Law, 9(2), 173-183. http://doi.org/10.1080/1068316031000116265

Almond, L., Alison, L., \& Porter, L. (2007). An evaluation and comparison of claims made in behavioral investigative advice reports compiled by the National Policing Improvements Agency in the United Kingdom. Journal of Investigative Psychology and Offender Profiling, 4(2), 71-83. http://doi.org/10.1002/jip.59

Almond, L., McManus, M., Bal, A., O’Brien, F., Rainbow, L., \& Webb, M. (2018). Assisting the Investigation of Stranger Rapes: Predicting the Criminal Record of U.K. Stranger Rapists From Their Crime Scene Behaviors. Journal of Interpersonal Violence. http://doi.org/10.1177/0886260518756118

Asendorpf, J. B., Conner, M., De Fruyt, F., De Houwer, J., Denissen, J. J. A., Fiedler, K., ... Wicherts, J. M. (2013). Recommendations for Increasing Replicability in Psychology. European Journal of Personality, 27(2), 108-119. http://doi.org/10.1002/per.1919

Beauregard, E., \& Bouchard, M. (2010). Cleaning up your act: Forensic awareness as a detection avoidance strategy. Journal of Criminal Justice, 38(6), 11601166. http://doi.org/10.1016/j.jcrimjus.2010.09.004 
Beauregard, E., \& Martineau, M. (2013). A descriptive study of sexual homicide in Canada: Implications for police investigation. International Journal of Offender Therapy and Comparative Criminology, 57(12), 1454-1476. http://doi.org/10.1177/0306624X12456682

Broidy, L. M., Daday, J. K., Crandall, C. S., Sklar, D. P., \& Jost, P. F. (2006). Exploring Demographic, Structural, and Behavioral Overlap Among Homicide Offenders and Victims. Homicide Studies, 10(3), 155-180. http://doi.org/10.1177/1088767906288577

Canter, D. V. (2011). Resolving the offender 'profiling equations' and the emergence of an investigative psychology. Current Directions in Psychological Science, 20(1), 5-10. http://doi.org/10.1177/0963721410396825

Chen, H., Cohen, P., \& Chen, S. (2010). How Big is a Big Odds Ratio? Interpreting the Magnitudes of Odds Ratios in Epidemiological Studies. Communications in Statistics - Simulation and Computation, 39(4), 860-864. http://doi.org/10.1080/03610911003650383

Cole, T., \& Brown, J. (2014). Behavioral investigative advice: Assistance to investigative decision-making in difficult-to-detect murder. Journal of Investigative Psychology and Offender Profiling, 11(3), 191-220. http://doi.org/10.1002/jip.1396

Crabbé, A., Decoene, S., \& Vertommen, H. (2008). Profiling homicide offenders: A review of assumptions and theories. Aggression and Violent Behavior, 13(2), 88-106. http://doi.org/10.1016/j.avb.2008.01.001

Cramer, J. S. (1999). Predictive Performance of the Binary Logit Model in Unbalanced Samples. Journal of the Royal Statistical Society: Series $D$ (The Statistician), 48(1), 85-94. http://doi.org/10.1111/1467-9884.00173

Davies, A., Wittebrood, K., \& Jackson, J. L. (1997). Predicting the criminal antecedents of a stranger rapist from his offence behavior. Science and Justice Journal of the Forensic Science Society, 37(3), 161-170. http://doi.org/10.1016/S1355-0306(97)72169-5

Fawcett, T. (2006). An introduction to ROC analysis. Pattern Recognition Letters, 27(8), 861-874. http://doi.org/10.1016/j.patrec.2005.10.010

Field, A. P. (2013). Discovering Statistics Using IBM SPSS Statistics (4th ed.). London: Sage. 
Francis, B., Barry, J., Bowater, R., Miller, N., Soothill, K., \& Ackerley, E. (2004). Using homicide data to assist murder investigations. Retrieved 28 December 2017, from http://eprints.lancs.ac.uk/9492/1/francishomicide2004.pdf

Fujita, G., Watanabe, K., Yokota, K., Suzuki, M., Wachi, T., Otsuka, Y., \& Kuraishi, H. (2016). A Multivariate Model for Analyzing Crime Scene Information: Predicting Stranger, Solo Offender, and Money-Oriented Motive of Japanese Homicides. Homicide Studies, 20(4), 295-320. http://doi.org/10.1177/1088767915613828

Goetting, A. (1991). Female victims of homicide: A portrait of their killers and the circumstances of their deaths. Violence and Victims. US: Springer Publishing.

Goodwill, A. M., Alison, L. J., \& Beech, A. R. (2009). What works in offender profiling? A comparison of typological, thematic, and multivariate models. Behavioral Sciences \& the Law, 27(4), 507-529. http://doi.org/10.1002/bsl.867

Greenall, P. V, \& Richardson, C. (2015). Adult Male-on-Female Stranger Sexual Homicide: A Descriptive (Baseline) Study From Great Britain. Homicide Studies, 19(3), 237-256. http://doi.org/10.1177/1088767914530555

Horning, A. M., Salfati, C. G., \& Crawford, K. (2010). Prior crime specialization and its relationship to homicide crime scene behavior type. Homicide Studies, 14(4), 377-399. http://doi.org/10.1177/1088767910382833

Innes, M. (2003). Investigating Murder: Detective Work and the Police Response to Criminal Homicide. Oxford University Press.

Jurik, N. C., \& Winn, R. (1990). Gender and homicide: a comparison of men and women who kill. Violence and Victims, 5(4), 227-242.

Lea, S. J., Hunt, L., \& Shaw, S. (2011). Sexual Assault of Older Women by Strangers. Journal of Interpersonal Violence, 26(11), 2303-2320. http://doi.org/10.1177/0886260510383036

Levine, T. R., Blair, J. P., \& Carpenter, C. J. (2017). A critical look at meta-analytic evidence for the cognitive approach to lie detection: A re-examination of Vrij, Fisher, and Blank (2017). Legal and Criminological Psychology, 7-19. http://doi.org/10.1111/lcrp.12115

Liberman, A. M. (2005). How Much More Likely? The Implications of Odds Ratios for Probabilities. American Journal of Evaluation, 26(2), 253-266. http://doi.org/10.1177/1098214005275825 
Mokros, A., \& Alison, L. J. (2002). Is offender profiling possible? Testing the predicted homology of crime scene actions and background characteristics in a sample of rapists. Legal and Criminological Psychology, 7(1), 25-43. http://doi.org/10.1348/135532502168360

Muftić, L. R., \& Baumann, M. L. (2012). Female Versus Male Perpetrated Femicide: An Exploratory Analysis of Whether Offender Gender Matters. Journal of Interpersonal Violence, 27(14), 2824-2844. http://doi.org/10.1177/0886260512438282

Nemes, S., Jonasson, J. M., Genell, A., \& Steineck, G. (2009). Bias in odds ratios by logistic regression modelling and sample size. BMC Medical Research Methodology, 9(1), 1-5. http://doi.org/10.1186/1471-2288-9-56

Nicol, C., Innes, M., Gee, D., \& Feist, A. (2004). Reviewing murder investigations: An analysis of progress reviews from six police forces. Retrieved 18 January 2018, from

http://webarchive.nationalarchives.gov.uk/20110223130954/http://rds. homeoffice .gov.uk/rds/pdfs04/r218.pdf

Pedneault, A., Harris, D. A., \& Knight, R. A. (2015). An examination of escalation in burglaries committed by sexual offenders. International Journal of Offender Therapy and Comparative Criminology, 59(11), 1203-1221. http://doi.org/10.1177/0306624X14533109

Pell, C. (2017). Body Part Removal: A Thematic Exploration of UK Homicide Offences. Unpublished MSc thesis, University of Liverpool.

Putkonen, H., Weizmann-Henelius, G., Lindberg, N., Rovamo, T., \& Häkkänennyholm, H. (2011). Gender differences in homicide offenders' criminal career, substance abuse and mental health care. A nationwide register-based study of Finnish homicide offenders 1995-2004. Criminal Behavior and Mental Health, 21(1), 51-62. http://doi.org/10.1002/cbm.782

Rainbow, L. (2008). Taming the Beast: The UK Approach to the Management of Behavioral Investigative Advice. Journal of Police and Criminal Psychology, 23(2), 90-97. http://doi.org/10.1007/s11896-008-9024-9

Rainbow, L., \& Gregory, A. (2009). Behavioral Investigative Advice: A contemporary view. The Journal of Homicide and Major Incident Investigation, 5(1), 71-82.

Ressler, R. K., Burgess, A. W., \& Douglas, J. E. (1988). Sexual homicide: Patterns and motives. New York: Lexington. 
Rice, M. E., \& Harris, G. T. (2005). Comparing effect sizes in follow-up studies: ROC area, Cohen's d, and r. Law and Human Behavior, 29(5), 615-620. http://doi.org/10.1007/s10979-005-6832-7

Salfati, C. G. (2000). The Nature of Expressiveness and Instrumentality in Homicide: Implications for Offender Profiling. Homicide Studies, 4(3), 265-293. http://doi.org/10.1177/1088767900004003004

Salfati, C. G., \& Canter, D. V. (1999). Differentiating stranger murders: Profiling offender characteristics from behavioral styles. Behavioral Sciences and the Law, $\quad$ 17(3), $\quad 391-406 . \quad$ http://doi.org/10.1002/(SICl)10990798(199907/09)17:3<391::AID-BSL352>3.0.CO;2-Z

Santtila, P., Häkkänen, H., Canter, D., \& Elfgren, T. (2003). Classifying homicide offenders and predicting their characteristics from crime scene behavior. Scandinavian Journal of Psychology, 44(2), 107-118. http://doi.org/10.1111/1467-9450.00328

Schlesinger, L. B., \& Revitch, E. (1999). Sexual burglaries and sexual homicide: clinical, forensic, and investigative considerations. The Journal of the American Academy of Psychiatry and the Law, 27(2), 227-238.

Scott, D., Lambie, I., Henwood, D., \& Lamb, R. (2006). Profiling stranger rapists: Linking offence behavior to previous criminal histories using a regression model. Journal of Sexual Aggression, 12(3), 265-275. http://doi.org/10.1080/13552600601090329

Soothill, K., Francis, B., Ackerley, E., \& Fligelstone, R. (2002). Murder and Serious Sexual Assault: What criminal histories can reveal about future serious $\begin{array}{llllll}\text { offending. } & \text { Retrieved } & 8 & \text { August } & \text { 2018, from }\end{array}$ http://eprints.lancs.ac.uk/3423/1/prs144.pdf

Taylor, P. J., Snook, B., Bennell, C., \& Porter, L. E. (2015). Investigative Psychology. In B. L. Cutler \& P. A. Zapf (Eds.), APA handbook of forensic psychology (Vol. 2, Criminal investigation, adjudication, and sentencing outcomes) (pp. 165-186). Washington, DC: American Psychological Association.

ter Beek, M., van den Eshof, P., \& Mali, B. (2010). Statistical modelling in the investigation of stranger rape. Journal of Investigative Psychology and Offender Profiling, 7(1), 31-47. http://doi.org/10.1002/jip.103 
Trägårdh, K., Nilsson, T., Granath, S., \& Sturup, J. (2016). A time trend study of swedish male and female homicide offenders from 1990 to 2010. International Journal of Forensic Mental Health, 15(2), 125-135. http://doi.org/10.1080/14999013.2016.1152615

Trojan, C., \& Salfati, C. G. (2011). Linking Criminal History to Crime Scene Behavior in Single-Victim and Serial Homicide: Implications for Offender Profiling Research. Homicide Studies, 15(1), 3-31. http://doi.org/10.1177/1088767910397281

Trojan, C., \& Salfati, C. G. (2016). Criminal history of homicide offenders: a multidimensional analysis of criminal specialization. Journal of Criminal Psychology, 6(1), 28-41. http://doi.org/10.1108/JCP-09-2015-0027

Wright, E. (2017). Focus on violent crime and sexual offences, England and Wales: year ending Mar 2016. Retrieved 8 December 2017, from https://www.ons.gov.uk/peoplepopulationandcommunity/crimeandjustice/compen dium/focusonviolentcrimeandsexualoffences/yearendingmarch2016/pdf 


\begin{tabular}{lll} 
Table 1 & \\
$\begin{array}{l}\text { Frequency of relationship } \\
\text { between offenders and their victims. }\end{array}$ \\
\hline categories \\
Offender-victim relationship & $\mathrm{n}$ & $(\%)$ \\
\hline Stranger & 71 & $(33.3)$ \\
Friend/associate & 37 & $(17.4)$ \\
Romantic partner & 35 & $(16.4)$ \\
Prostitute & 25 & $(11.7)$ \\
Unknown & 21 & $(9.9)$ \\
Peripheral contact & 11 & $(5.2)$ \\
Romantic ex-partner & 9 & $(4.2)$ \\
Family & 4 & $(1.9)$ \\
\hline
\end{tabular}




\section{Table 2. Frequencies of offenders' crime}

scene behaviors during the index homicide.

Offence Behavior Variables $\quad n$

\begin{tabular}{|c|c|c|}
\hline \multirow{2}{*}{\multicolumn{3}{|c|}{ Precautionary behaviors }} \\
\hline & & \\
\hline Any precautions taken ${ }^{a}$ & 87 & $(40.8)$ \\
\hline Precautions scene & 55 & $(25.8)$ \\
\hline Precautions victim & 28 & $(13.1)$ \\
\hline Precautions offender & 16 & $(7.5)$ \\
\hline \multicolumn{3}{|l|}{ Sexual behaviors } \\
\hline Any overt sexual behaviors ${ }^{a}$ & 89 & $(41.8)$ \\
\hline Vaginal penetration & 67 & $(31.5)$ \\
\hline Anal penetration & 30 & $(14.1)$ \\
\hline Oral penetration & 8 & $(3.8)$ \\
\hline Other sexual activity & 24 & $(11.3)$ \\
\hline Offence Behavior Variables & $\mathrm{n}$ & $(\%)$ \\
\hline Any disrobement ${ }^{a}$ & 141 & $(66.2)$ \\
\hline Victim naked & $\begin{array}{l}141 \\
56\end{array}$ & $(26.3)$ \\
\hline Victim partially disrobed & 52 & $(24.4)$ \\
\hline Clothing moved to expose & 34 & $(16.0)$ \\
\hline Injury to sexual areas & 35 & $(16.4)$ \\
\hline Sexual homicide $a, b$ & 156 & $(73.2)$ \\
\hline \multicolumn{3}{|l|}{ Body disposal } \\
\hline Body recovered indoors & 113 & $(53.1)$ \\
\hline Body concealed & 53 & $(24.9)$ \\
\hline Body dismembered & 18 & $(8.5)$ \\
\hline \multicolumn{3}{|l|}{ Weapon involvement } \\
\hline Any weapon involved ${ }^{a}$ & 142 & $(66.7)$ \\
\hline Stabbing weapon & 73 & $(34.3)$ \\
\hline Bludgeoning weapon & 45 & $(21.1)$ \\
\hline Ligature weapon & 44 & (20.7) \\
\hline Weapon taken from scene & 56 & $(26.3)$ \\
\hline Weapon brought by offender & 33 & $(15.5)$ \\
\hline \multicolumn{3}{|l|}{ Theft } \\
\hline Any theft ${ }^{a}$ & 94 & (44.1) \\
\hline Theft valuables & 77 & $(36.2)$ \\
\hline Theft personal & 34 & $(16.0)$ \\
\hline Theft clothing & 28 & $(13.1)$ \\
\hline \multicolumn{3}{|l|}{ Method of killing } \\
\hline Death blunt force & 81 & $(38.0)$ \\
\hline Death asphyxia/strang. & 73 & $(34.3)$ \\
\hline Death sharp force & 49 & $(23.0)$ \\
\hline \multicolumn{3}{|l|}{ Other behaviors } \\
\hline Vehicle used & 55 & $(25.8)$ \\
\hline Overkill & 47 & $(22.1)$ \\
\hline Burglary element & 45 & $(21.1)$ \\
\hline Arson element & 9 & $(4.2)$ \\
\hline
\end{tabular}

Notes. ${ }^{a}$ Variables printed in italics are collapsed behavior categories for descriptive purposes and were not included in the statistical analysis. ${ }^{b}$ Cases were classified by the author as sexual homicides according to the criteria proposed by Ressler et al. (1988). 
Table 3. Frequencies of offenders' previous convictions at the time of the index homicide.

\begin{tabular}{lll} 
Conviction Variables & $\mathrm{n}$ & $(\%)$ \\
\hline Criminal record & 157 & $(73.7)$ \\
Theft & 96 & $(45.1)$ \\
Violence & 83 & $(39.0)$ \\
Burglary & 75 & $(35.2)$ \\
Criminal damage & 71 & $(33.3)$ \\
Public order & 48 & $(22.5)$ \\
Fraud & 45 & $(21.1)$ \\
Weapons & 39 & $(18.3)$ \\
Sexual & 31 & $(14.6)$ \\
Robbery & 26 & $(12.2)$ \\
Drugs & 25 & $(11.7)$ \\
Arson & 10 & $(4.7)$ \\
Homicide & 8 & $(3.8)$ \\
\hline
\end{tabular}


Table 4

Odds Ratios for significant associations between crime scene behavior and conviction variables.

\begin{tabular}{|c|c|c|c|c|c|c|}
\hline & Burglary & $\begin{array}{l}\text { Criminal } \\
\text { Damage }\end{array}$ & Fraud & Theft & Weapons & Violence \\
\hline Precautions scene & & & & & 0.36 & \\
\hline Vaginal penetration & & & & 0.48 & 0.42 & 0.51 \\
\hline Victim naked & & & 2.01 & & & \\
\hline $\begin{array}{l}\text { Clothing moved to } \\
\text { expose }\end{array}$ & & & & & & 0.43 \\
\hline $\begin{array}{l}\text { Weapon brought by } \\
\text { offender }\end{array}$ & & 0.39 & & 0.40 & & 0.30 \\
\hline Bludgeoning weapon & & & 2.30 & & & \\
\hline Death blunt force & & 1.86 & & & & \\
\hline Death asphyxia/strang. & & & & & 0.29 & \\
\hline Vehicle used & & 0.41 & & & & \\
\hline Burglary element & 2.62 & & & & & \\
\hline Arson element & 7.00 & & & & & 5.89 \\
\hline
\end{tabular}

Table 5 
Crime scene behaviors differentiating offenders with and without a pre-convictions. Burglary Pre-conviction

Yes $(n=75) \quad$ No $(n=138) \quad$ Sig.

Burglary element

$32.0 \%$

$15.2 \%$

.005

\section{Criminal Damage Pre-conviction}

Vehicle used

Yes $(\mathrm{n}=71)$

No $(\mathrm{n}=142$

$15.5 \%$

$31.0 \%$

.016

Death blunt force

$47.9 \%$

$33.1 \%$

.034

Fraud Pre-conviction

Yes $(\mathrm{n}=45) \quad$ No $(\mathrm{n}=168)$

Victim naked

$37.8 \%$

$23.2 \%$

$17.9 \%$

.050

$33.3 \%$

.026

Theft Pre-conviction

Yes $(\mathrm{n}=96) \quad$ No $(\mathrm{n}=117)$

Vaginal penetration

$22.9 \%$

$38.5 \%$

.014

Weapon brought by offender

$9.4 \%$

$20.5 \%$

.025

Weapons Pre-conviction

Yes $(\mathrm{n}=39) \quad$ No $(\mathrm{n}=174)$

Precautions scene

$12.8 \%$

$28.7 \%$

.039

Death asphyxia/strang.

$15.4 \%$

$38.5 \%$

.007

Violence Pre-conviction

Yes $(\mathrm{n}=83) \quad$ No $(\mathrm{n}=130)$

Vaginal penetration

$22.9 \%$

$36.9 \%$

.028

Weapon brought by offender

$7.2 \%$

$20.8 \%$ 
Table 6

Logit values, AUCs, and percentage improvements in correctly predicted cases compared to a base rate "best guess" for logistic regression models.

Burglary $\begin{aligned} & \text { Criminal Fraud Theft Weapons Violence } \\ & \text { Damage }\end{aligned}$

\begin{tabular}{|c|c|c|c|c|c|c|}
\hline Model constant & -.830 & -.744 & -1.744 & .171 & -.954 & -.076 \\
\hline Precautions scene & & & & & -1.061 & \\
\hline Vaginal penetration & & & & -.768 & & -.710 \\
\hline Victim naked & & & .712 & & & \\
\hline $\begin{array}{l}\text { Weapon brought by } \\
\text { offender }\end{array}$ & & & & -.949 & & -1.246 \\
\hline Bludgeoning weapon & & & .847 & & & \\
\hline Death blunt force & & .640 & & & & \\
\hline $\begin{array}{l}\text { Death } \\
\text { asphyxia/strang. }\end{array}$ & & & & & -1.274 & \\
\hline Vehicle used & & -.915 & & & & \\
\hline Burglary element & .964 & & & & & \\
\hline
\end{tabular}

\begin{tabular}{|c|c|c|c|c|c|c|}
\hline$A \cup C$ & .584 & .623 & .626 & .624 & .662 & .622 \\
\hline$[95 \% \mathrm{Cl}]$ & $\begin{array}{l}{[.502,} \\
.666]\end{array}$ & $\begin{array}{l}{[.545} \\
.701]\end{array}$ & $\begin{array}{l}{[.532} \\
.721]\end{array}$ & $\begin{array}{l}{[.549} \\
.699]\end{array}$ & $\begin{array}{l}{[.576} \\
.748]\end{array}$ & $\begin{array}{l}{[.547} \\
.697]\end{array}$ \\
\hline $\begin{array}{l}\text { Difference to "best } \\
\text { guess" in \% correct }\end{array}$ & $+1.4 \%$ & $-^{*}$ & $-^{*}$ & $\begin{array}{l}+6.1 \\
\%\end{array}$ & $-^{*}$ & $-^{*}$ \\
\hline
\end{tabular}

Note. * No difference between \% pre-convictions predicted correctly using logistic regression model and \% correct using only base-rate information from the sample. 